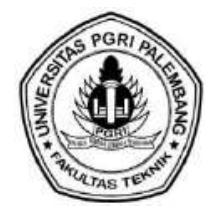

\title{
PENGARUH DAYA DUKUNG TANAH TERHADAP OPERASIONAL ALAT BERAT BUCKET WHEEL EXCAVATOR PADA PEKERJAAN BATUBARA DI PT. BUKIT ASAM Tbk TANJUNG ENIM
}

\author{
Yuliantini Eka Putri ${ }^{1}$, Enda Kartika Sari ${ }^{{ }^{*}}$ \\ ${ }^{12}$ Program Studi Teknik Sipil Fakultas Teknik dan Komputer Universitas Baturaja \\ *Corresponding Author, Email: endaunbara@gmail.com
}

\begin{abstract}
ABSTRAK
PT.Bukit Asam (persero) Tbk. merupakan perusahaan tambang kelas dunia yang terintegrasi menjadi perusahaan energi yang berkelanjutan. Perusahaan menguasai beberapa kuasa pertambangan dengan total sumber daya batu bara sebesar 7,29 milyar ton dan total cadangan batu bara yang dapat di tambang sebesar 1,99 milyar ton. Sehingga untuk meningkatkan produksi diperlukan alat penggali tambang seperti Bucket Wheel Excavator (BWE). Tujuan penelitian ini adalah menganalisa pengaruh daya dukung tanah terhadap operasional Bucket Wheel Excavator di PT.Bukit Asam (Persero) Tbk Tanjung Enim dengan metode ASTM S 1586-58 T. Daya dukung tanah yang diperoleh dari uji kuat tekan tanah, dari hasil uji Dynamic Penetration Test (DPT) dengan hasil 6 titik harus di kompaksi yaitu di titik 3 dengan $q c=179.34 \mathrm{kpa}$ di kedalaman 0.9 meter, titik 4 dengan $q c=194.29 \mathrm{kpa}$ di kedalaman 1.1 meter, titik 5 dengan qc=194.29 kpa di kedalaman 0.8 meter, titik 7 dengan qc=194.29 di kedalaman 1meter, titik 9 dengan $q c=224.18 \mathrm{kpa}$ di kedalaman 0.9 meter, dan titik 10 dengan qc=194.29 kpa di kedalaman 1.1meter. Setelah semua titik di kompaksi maka di uji lagi menggunakan alat Dutch Cone Penetrometer (DCP/sondir) dimana hasil uji DCP di 6 titik yang dikompaksi menghasilkan nilai CBR > 6\% sehingga ke 6 titik tersebut aman dan bisa di lalui Bucket Wheel Excavator.
\end{abstract}

Kata Kunci : Daya Dukung Tanah, BWE, DPT, DCP

\section{PENDAHULUAN}

PT. Bukit Asam (Persero) Tbk. merupakan perusahaan tambang kelas dunia yang terintegrasi menjadi perusahaan energi yang berkelanjutan. PT. Bukit Asam (Persero) Tbk telah beroperasi lebih dari 30 tahun secara terus menerus dan mampu mengoptimalkan tingkat profitabilitas dan menjaga kesinambungan usaha. Perusahaan menguasai beberapa kuasa pertambangan dengan total sumber daya batubara sebesar 7,29 milyar ton dan total cadangan batu bara yang dapat di tambang sebesar 1,99 milyar ton, sehingga untuk meningkatkan produksi diperlukan alat penggali tambang seperti Bucket Wheel Excavator (BWE).

Dalam perencanaan dan pekerjaan di pertambangan, tanah mempunyai peranan yang sangat penting. Tanah berfungsi sebagai penahan beban akibat alat berat di atas tanah dan harus bisa memikul seluruh beban alat berat beserta bangunan pendukungnya, kemudian dapat meneruskannya ke dalam tanah sampai ke lapisan atau kedalaman tertentu, sehingga kuat atau tidak nya alat berat serta bangunan pendukung itu juga dipengaruhi oleh kondisi tanah yang ada.

Kegiatan penambangan di PT.Bukit Asam (Persero) Tbk Tanjung Enim, memerlukan sarana dan prasarana dalam pelaksanaannya yang sebagian besar menggunakan alat berat dalam operasional penambangan, salah satunya adalah Bucket Wheel Excavator (BWE). Dalam 
operasionalnya BWE akan selalu berpindah dari satu tempat ke tempat yang lain, dan dalam pergerakannya tentu memerlukan landasan (jalan) yang kuat sehingga alat BWE akan aman dalam perpindahannya. Tentu dalam hal ini jalan (tanah) harus mempunyai daya dukung yang kuat agar alat BWE tidak terperosok saat melalui jalan tersebut.

Berdasarkan latar belakang di atas rumusan masalah penelitian ini adalah bagaimana pengaruh daya dukung tanah untuk menahan alat BWE dalam operesional pekerjaan di PT.Bukit Asam (Persero) Tbk Tanjung Enim. Tujuan penelitian ini adalah menganalisa pengaruh daya dukung tanah terhadap operasional Bucket Wheel Excavator di PT.Bukit Asam (Persero) Tbk Tanjung Enim dengan metode ASTM S 1586-58 T

\section{TINJAUAN PUSTAKA}

\section{Bucket Wheel Excavator (B.W.E.)}

BWE adalah alat berat yang memiliki dimensi sangat besar, digunakan pada tambang terbuka seperti penambangan batubara serta memiliki roda berputar yang sangat besar dan dipasangkan kepada lengan. Ujung roda ini kemudian dipasangi semacam ember besi (Bucket) dengan gigi-gigi logam (teeth) dipinggiran bucket yang berfungsi untuk mengeruk batubara di permukaan. Link Track digunakan sebagai bantalan untuk pemegang roda rantai BWE. BWE sendiri memiliki dimensi yang sangat besar sehingga mengakibatkan beban yang diterima oleh bagian rantai roda cukup besar (Bandanadjaja, B., \& Achyarsyah, M, 2017).

B.W.E. adalah alat berat yang digunakan pada surface mining, dengan fungsi utama sebagai mesin penggali secara terus menerus (continuous digging machine) dalam skala besar pada penambangan terbuka. Sistem pengoperasiannya paling efektif digunakan di tanah-lunak yang tidak banyak mengandung batuan keras seperti halnya di tambang batubara. Komponen utama B.W.E. adalah roda berputar besar (bucket wheel) yang seperti piringan besar pada sebuah lengan raksasa secara vertikal dengan beberapa ember besi/baja (bucket) bergigi-gigi logam di bagian ujung bucket.

Penggalian pada B.W.E. dilakukan oleh sebuah arm yang diujungnya terdapat roda besar dimana di sekelilingnya dipasang mangkuk-mangkuk (bucket). Arm beserta mangkuk-mangkuknya yang berputar pada rodanya ditekan ke arah material yang akan diangkut. Setelah mangkuk-mangkuk tersebut terisi penuh, selanjutnya ditumpahkan ke belt conveyor yang sudah terpasang sebagai alat angkut. Denganj umlah bucket yang banyak maka penggalian dengan B.W.E. dapat dilakukan secara terus menerus (continuous).

\section{Tanah.}

Tanah adalah kumpulan butiran (agregat) mineral alami yang bisa dipisahkan oleh suatu cara mekanik bila agregat tersebut diaduk dalam air (Terzaghi, 1987). Selain itu dalam arti lain tanah merupakan akumulasi partikel mineral yang tidak mempunyai ikatan antar partikelnya, yang terbentuk karena pelapukan dari batuan. 


\section{Tanah Organik}

Menurut Bohnethal (1979) tanah organik memiliki tekstur terbuka dimana selain pori-pori makro, tekstur tanah organik juga didominasi oleh pori-pori mikro yang berada di dalam serat-serat organik. Dengan sistem pori ganda dan tingkat homogenitas yang tidak merata tersebut, serta berat isi tanah yang mendekati berat isi air, maka masalah pemampatan (compressibility) yang besar bisa mengakibatkan penurunan (settlement) yang besar juga. Selain itu karena tanah organik ini sangat lembek pada umumnya mempunyai daya dukung (bearing capacity) yang rendah. Tanah jenis ini umumnya mudah mengalami penurunan yang besar. perilaku tanah organik sangat tergantung pada kadar organik (organic content), kadar abu (ash content), kadar serat (fibrous content). Makin tinggi kandungan organiknya makin rendah daya dukungnya (bearing capacity) dan kekuatan gesernya (shear strength).

Perilaku dan sifat tanah organik sangat tergantung pada komposisi mineral dan unsurunsur kimianya, tekstur dan partikel-partikelnya serta pengaruh lingkungan di sekitarnya. Sehingga untuk dapat memahami sifat dan perilakunya diperlukan pengetahuan tentang mineral dan komposisi kimia gambut. Hal ini dikarenakan mineralogi adalah faktor utama untuk mengontrol ukuran, bentuk, dan sifat fisik serta kimia dari partikel gambut. Sampai saat ini pengetahuan tentang gambut masih sangat sedikit sekali. Oleh karena itu, pemecahan dengan metode yang benar dan tepat adalah sangat diharapkan agar konstruksi yang dibangun dapat berdiri dengan kuat dan aman. Di dalam rekayasa geoteknik telah lama dikenal beberapa cara bagaimana memanfaatkan tanah asli yang memenuhi syarat/ sebagai material konstruksi, misalnya pada tanah lunak, gambut dan sebagainya. Hasil dari upaya rekayasa tersebut didapat keadaan tanah dengan daya dukung yang lebih baik serta sifat-sifat lainnya yang positif dilihat dari sudut pandang konstruksi. Sehingga sifat-sifat dan karakteristik tanah tersebut menjadi memadai sebagai material konstruksi.

\section{Sifat - Sifat Fisik Tanah}

Tanah gambut mempunyai sifat beragam karena perbedaan bahan asal, proses pembentukan dan lingkungannya. Pada umumnya tanah gambut berwarna coklat tua meskipun bahan asalnya berwarna hitam, coklat, atau kemerah-merahan. Setelah mengalami dekomposisi terdapat senyawa-senyawa asam humik berwarna gelap. Tanah gambut mempunyai sifat-sifat yang menonjol antara lain : a) kerapatan massa yang lebih bila dibandingkan dengan tanah mineral; b) kecilnya berat tanah gambut bila kering; c) kemampuan menahan air tinggi; d) mengenai stukturnya yaitu keadaan fisik yang hampir tidak berubah.

Sifat fisik tanah gambut lainnya adalah sifat mengering tidak balik. Gambut yang telah mengering, dengan kadar air $<100 \%$ (berdasarkan berat), tidak bisa menyerap air lagi kalau dibasahi. Gambut yang mengering ini sifatnya sama dengan kayu kering yang mudah hanyut dibawa aliran air dan mudah terbakar dalam keadaan kering. Gambut yang terbakar menghasilkan energi panas yang lebih besar dari kayu/arang terbakar. Sifat-sifat fisik tanah berhubungan erat dengan kelayakan pada banyak penggunaan tanah. Kekokohan dan kekuatan pendukung, kapasitas penyimpanan air, plastisitas semuanya secara erat berkaitan dengan kondisi fisik tanah. Tidak berbeda 
dengan tanah lempung, parameter tanah yang penting untuk menentukan sifat fisik tanah gambut di antaranya : berat volume, specific gravity, kadar air, dan angka pori. Sedang parameter tanah gambut yang tidak diperlukan untuk tanah lempung adalah: kadar abu, kadar organik, dan kadar serat. Pada tanah lempung, dimana plastisitasnya sangat diperlukan untuk mengidentifikasi sifat tanah, pada tanah gambut sama sekali tidak diperlukan, mengingat tanah gambut tidak mempunyai sifat plastis. Penggaliannya langsung dimuat ke alat angkut yang biasanya berupa rangkaian belt conveyor atau belt wagon, maka B.W.E. juga berfungsi sebagai alat muat. Kelebihan B.W.E. dapat memberikan tingkat produksi yang tinggi karena kerjanya yang terus menerus dan mesin raksasa ini dioperasikan dengan sistem hidrolik. Kelemahan pada B.W.E. adalah pada harga alat yang sangat tinggi dan karakteristik mesin yang hanya cocok digunakan di tanah yang relatif lunak.

\section{Daya Dukung Tanah.}

Daya dukung tanah adalah besarnya tekanan atau kemampuan tanah untuk menerima beban dari luar sehingga menjadi stabil. Kapasitas daya dukung pondasi dangkal berhubungan dengan perancangan dalam bidang geoteknik (Zakaria, Z, 2006). Kapasitas/daya dukung tanah (bearing capacity) adalah kekuatan tanah untuk menahan suatu beban yang bekerja padanya yang biasanya disalurkan melalui alat berat dan bangunan pendukung lainnya. Kapasitas/dayadukung tanah batas $(\mathrm{qu}=\mathrm{qul} \mathrm{t}=$ ultimate bearing capacity $)$ adalah tekanan maksimum yang dapat diterima oleh tanah akibat beban yang bekerja tanpa menimbulkan kelongsoran geser pada tanah pendukung tepat di bawah alat berat dan bangunan pendukung lainnya.

$$
m=N \times 14.5 \mathrm{kpa} \text {. }
$$

\section{persamaan 1}

\section{California Bearing Ratio (CBR)}

CBR (Lindawati, L., \& Sari, E. K, 2019) adalah perbandingan antara beban penetrasi suatu beban terhadap bahan standar dengan kedalaman dan kecepatan penetrasi yang sama cara umum dan merupakan suatu perbandingan antara beban percobaan (test load) dengan beban standar (standard load) dan dinyatakan dalam persentase California Bearing Ratio (CBR) laboratorium adalah perbandingan antara beban penetrasi suatu bahan terhadap bahan standar dengan kedalaman dan kecepatan penetrasi yang sama. Tekanan yang diperlukan untuk penetrasi piston berbentuk lingkaran dengan luas 3 in2 (1935 mm2) yang ditekan masuk ke dalam tanah yang diletakkan dalam cetakan khusus dengan kecepatan penetrasi 1 mm/menit (Diana, W., Marianti, A., \& Ernawati, I ,2015).

Uji Californian Bearing Ratio (CBR) adalah uji penetrasi yang digunakan untuk mengevaluasi kekuatan tanah dasar jalan dan perkerasan. Hasil pengujian ini digunakan dengan kurva untuk menentukan ketebalan trotoar dan lapisan komponennya. Ini adalah metode yang paling banyak digunakan untuk desain perkerasan lentur. Menurut Lindawati, L., \& Sari, E. K. (2019) CBR disebut CBR laboratorium karena disiapkan dilaboratorium. Dimana tanah dasar (subgrade) pada kontruksi jalan baru dapat berupa tanah asli, tanah timbunan atau tanah galian yang telah dipadatkan sampai mencapai kepadatan $(95 \%)$ kepadatan maksimum. 
Di Indonesia kapasitas dukung tanah dasar untuk kebutuhan perencanaan tebal perkerasan umumnya ditentukan dengan melakukan pengujian CBR. Berdasarkan cara mendapatkannya, uji CBR dapat dilakukan dengan 3 kondisi, salah satunya adalah CBR lapangan (field CBR) dengan menggunakan hasil pemeriksaan DCP. Pemeriksaan dengan alat DCP menghasilkan data kekuatan dukung tanah sampai kedalaman $90 \mathrm{~cm}$ di bawah tanah dasar. Hasil pemeriksaan ini dinyatakan dengan Penetrabilitas Skala Penetrometer (SPP) dan Tahanan Penetrasi Skala (SPR). SPP dinyatakan dalam satuan cm/tumbukan sementara SPR dinyatakan dalam tumbukan $/ \mathrm{cm}$. Untuk tanah, evaluasi kuat geser yang diperoleh dari uji sondir memberikan indikasi yang cukup baik. Untuk mendapatkan nilai CBR in-situ, uji sondir dapat digunakan berdasarkan korelasi empiris yang juga dapat dilakukan lebih dahulu di laboratorium.mendapatkan korelasi untuk tanah sebagai berikut :

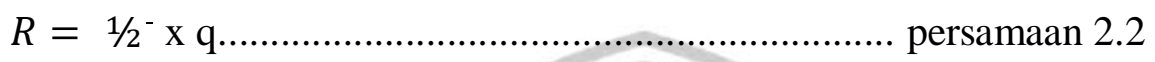

\section{Kompaksi}

Menurut Karno, K. (2020), kompaksi atau pemadatan adalah proses yang memakai tenaga dinamik untuk menjadikan tanah lebih padat dan sekaligus mengeluarkan udara. Kadar air tanah tidak berubah ketika tanah itu dipadatkan.Tujuan dilakukan kompaksi adalah untuk mendapatkan kepadatan yang maksimum, peningkatan stabilitas volume dari tanah. Sedangkan pengertian dari kompaksi itu sendiri adalah usaha untuk mempertinggi kerapatan tanah dengan mendesak udara keluar dari pori-pori tanah secara mekanis, yaitu dengan cara menumbuk, menggilas atau menggetarkan. Dengan kompaksi udara didalam pori-pori tanah tidak dapat dikeluarkan seluruhnya, tapi dengan pelaksanaan dan pengontrolan yang baik akan didapatkan volume udara yang minimum dalam pori-pori.

\section{METODE PENELITIAN}

Lokasi dan waktu penelitian dilaksanakan di PT. Bukit Asam (Persero),Tbk Tanjung Enim yang berlokasi di Jl. Parigi No.1 , Tanjung Enim 31716, Sumater Selatan. Data yang digunakan dalam penelitian ini adalah data primer dan data sekunder. Data primer didapatkan dengan cara pengamatan langsung di lapangan dan wawancara dengan narasumber yang berkaitan langsung dengan bidang kerja. Data sekunder adalah data yang diperoleh secara tidak langsung atau diperoleh dari buku - buku penunjang yang berhubungan dengan masalah yang dibahas berupa buku referensi, penelitian - penelitian terdahulu. Analisa dilakukan dengan pengujan langsung terhadap daya dukung tanah dengan alat Dynamic Penetration Test (DPT) dan alat Dutch Cone Penetrometer (DCP/Sondir), selanjutnya analisis data dilakukan dengan menggunakan analisa ASTM S 1586-58 T

\section{HASIL DAN PEMBAHASAN}

Dari hasil perhitungan dan analisa yang dilakukan terhadap daya dukung tanah dengan menggunakan alat uji Dynamic Penetration Test (DPT) dengan tipe alat Cat.T13, 
kapasitas alat $500 \mathrm{kPa}$ dan daya dukung tanah dipersyaratkan $>110 \mathrm{kPa}$ terdapat 6 titik lokasi tanah yang harus di kompaksi yaitu di titik 3 dengan qc $=179.34 \mathrm{kpa}$ di kedalaman 0.9 meter, titik 4 dengan $\mathrm{qc}=194.29 \mathrm{kpa}$ di kedalaman 1,1 meter, titik 5 dengan $\mathrm{qc}=$ $194.29 \mathrm{kpa}$ di kedalaman 0.8 meter, titik 7 dengan qc $=194.29$ di kedalaman 1 meter, titik 9 dengan $\mathrm{qc}=224.18 \mathrm{kpa}$ di kedalaman 0.9 meter, dan titik 10 dengan $\mathrm{qc}=194.29 \mathrm{kpa}$ di kedalaman 1,1 meter. Dan dapat dilihat pada gambar dan tabel berikut :

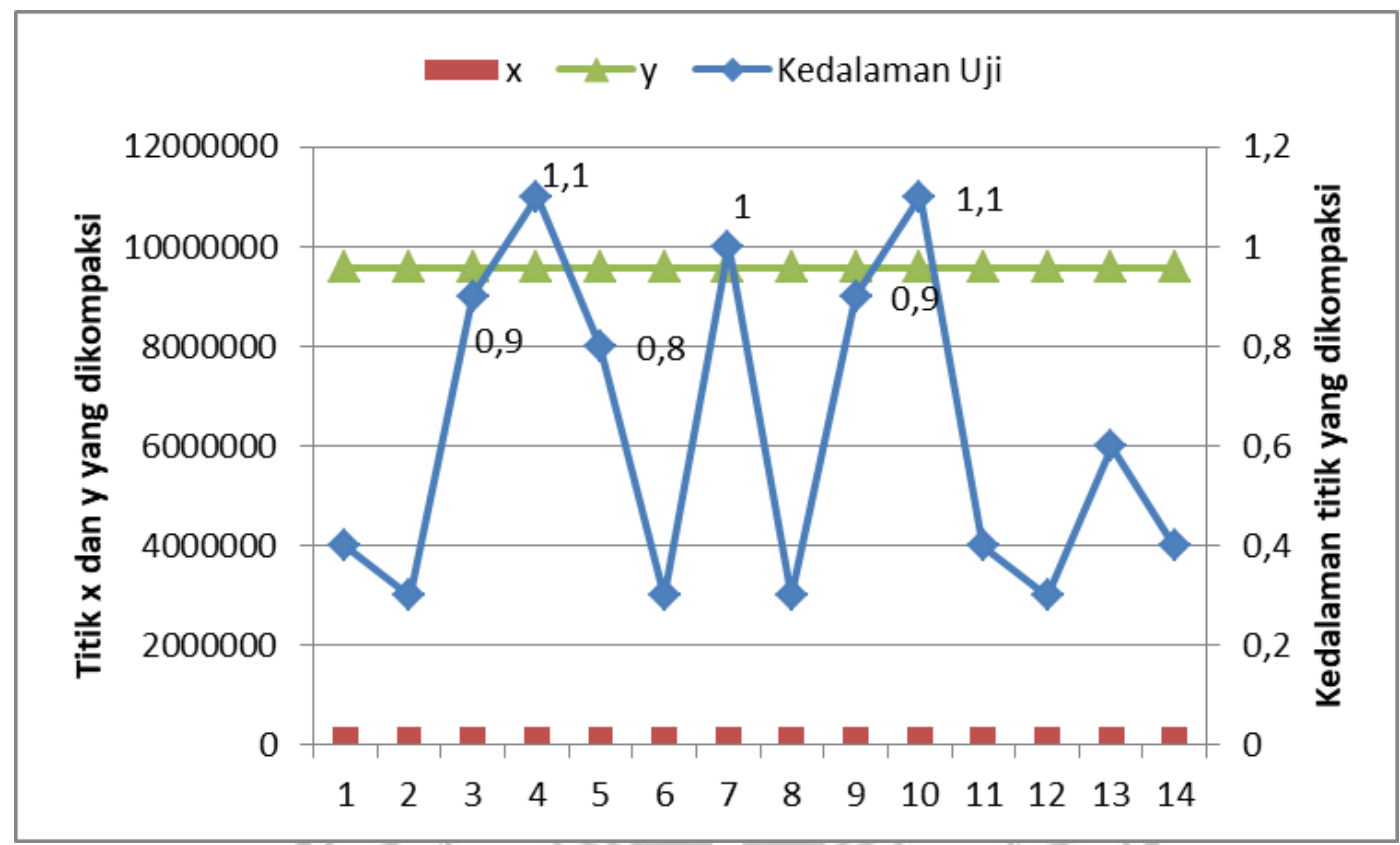

Gambar 1. Layout Titik Yang Dikompaksi

Tabel 1. Pengujian Kedalam Titik Yang Dikompaksi

\begin{tabular}{|c|c|c|c|c|}
\hline \multirow{2}{*}{$\begin{array}{c}\text { No } \\
\text { DPT }\end{array}$} & \multicolumn{2}{|c|}{ Koordinat } & \multirow{2}{*}{$\begin{array}{c}\text { Kedalaman } \\
\text { Uji }\end{array}$} & Resume Pengujian \\
\cline { 2 - 3 } & $\mathrm{x}$ & $\mathrm{y}$ & 0,4 & OK \\
\hline 1 & 365020 & 9586524 & 0,3 & OK \\
\hline 2 & 365031 & 9586519 & 0,9 & DIKOMPAKSI \\
\hline 3 & 365034 & 9586511 & 1,1 & DIKOMPAKSI \\
\hline 4 & 365025 & 9586509 & 0,8 & DIKOMPAKSI \\
\hline 5 & 365024 & 9586501 & 0,3 & OK \\
\hline 6 & 365031 & 9586501 & 1 & DIKOMPAKSI \\
\hline 7 & 365038 & 9586494 & 0,3 & OK \\
\hline 8 & 365027 & 9586486 & 0,9 & DIKOMPAKSI \\
\hline 9 & 365022 & 9586483 & 1,1 & DIKOMPAKSI \\
\hline 10 & 365026 & 9586492 & 0,4 & OK \\
\hline 11 & 364356 & 9586173 & 0,3 & OK \\
\hline 12 & 365026 & 9586166 & 0,6 & OK \\
\hline 13 & 365026 & 9586172 & 0,4 & OK \\
\hline 14 & 365026 & 9586179 & & \\
\hline
\end{tabular}


Dari Tabel 2 terlihat bahwa dari 14 titik uji DDT ada 6 titik yang nilai DDT nya tidak memenuhi standar yang mana nilai DDT nya tidak dapat menahan berat BWE yang akan melalui jalan tempat titik uji. Dan dari ke 6 titik tersebut nilai DDT yang terbesar terjadi di titik 9 sebesar $224,18 \mathrm{kPa}$ setara dengan 2286 ton/m2

Dan selanjutnya di ke 6 titik tersebut dilakukan kompaksi, dimana setelah semua titik di kompaksi maka di uji lagi dengan menggunakan alat Dutch Cone Penetrometer (DCP/Sondir) dimana hasil uji aman dan bisa dilalui Bucket Wheel Excavator (BWE) untuk perpindahan dari tempat sebelum nya ke tempat yang telah ditentukan. Hal ini dapat dilihat dari tabel berikut :

Tabel 2. Hasil Kompaksi DCP

\begin{tabular}{|c|c|c|c|c|c|}
\hline \multirow{2}{*}{ Nomor } & \multicolumn{2}{|c|}{ Koordinat WGS 1984 } & \begin{tabular}{c} 
Total Keda- \\
\cline { 2 - 3 } laman $(\mathrm{mm})$
\end{tabular} & $\begin{array}{c}\text { Rentang Nilai } \\
\text { CBR }(\%)\end{array}$ & $\begin{array}{c}\text { Rekomendasi } \\
\text { / Saran }\end{array}$ \\
\hline DCL01 & 364625 & 9586311 & 75 & $14-50$ & OK \\
\hline DCL02 & 364651 & 9586308 & 20 & $50-100$ & OK \\
\hline DCL03 & 364665 & 9586326 & 17 & $20-100$ & OK \\
\hline DCL04 & 364687 & 9586327 & 30 & $20-100$ & OK \\
\hline DCL05 & 634703 & 9586344 & 16 & $20-100$ & OK \\
\hline DCL06 & 364728 & 9586349 & 40 & $14-100$ & OK \\
\hline DCL07 & 364743 & 9586367 & 25 & $25-100$ & OK \\
\hline DCL08 & 364766 & 9586368 & 20 & $18-100$ & OK \\
\hline DCL09 & 364784 & 9586386 & 25 & $20-100$ & OK \\
\hline DCL10 & 364809 & 9586383 & 25 & $15-100$ & OK \\
\hline DCL11 & 364828 & 9586402 & 30 & $20-100$ & OK \\
\hline DCL12 & 364853 & 9586398 & 60 & $10-100$ & OK \\
\hline DCL13 & 364871 & 958420 & 62 & $14-100$ & OK \\
\hline DCL14 & 364899 & 958413 & 20 & $24-100$ & OK \\
\hline
\end{tabular}

\section{KESIMPULAN}

Hasil uji Dynamic Penetration Test (DPT) terdapat 6 titik yang harus di kompaksi yaitu di titik 3 dengan qc $=179.34$ kpa di kedalaman 0.9 meter, titik 4 dengan $q c=194.29$ kpa di kedalaman 1,1 meter, titik 5 dengan qc $=194.29$ kpa di kedalaman 0.8 meter, titik 7 dengan qc $=194.29$ di kedalaman 1 meter, titik 9 dengan qc $=224.18$ kpa di kedalaman 0.9 meter, dan titik 10 dengan qc $=194.29$ kpa di kedalaman 1,1 meter. Sehingga ke 6 titik tersebut dilakukan kompaksi dengan alat Dutch Cone Penetrometer (DCP/Sondir) dimana hasil ujinya aman dan bisa dilalui Bucket Wheel Excavator untuk perpindahan dari tempat sebelum nya ke tempat yang telah ditentukan

\section{DAFTAR PUSTAKA}

Bandanadjaja, B., \& Achyarsyah, M. (2017). Perancangan Material Coran Baja Link Track untuk Bucket Wheel Excavator Batubara. Creative Research Journal, 1(01), 47-63. 
Diana, W., Marianti, A., \& Ernawati, I. (2015). Optimasi Kadar Aspal pada Stabilisasi Tanah Pasir Menggunakan Aspal dengan Uji CBR. Semesta Teknika, 14(2), 127132.

Karno, K. (2020). Analisis Jumlah Gilasan Uji Kompaksi Plat Getar Pada Tanah Urug. Jurnal Student Teknik Sipil, 2(1), 92-98.

Lindawati, L., \& Sari, E. K. (2019). Analisa Pengaruh Penambahan Limbah Gypsum Terhadap Nilai CBR Tanah Dasar di Ruas Jalan BK 1 Desa Tanjung Bulan Kabupaten OKU Timur. Jurnal Deformasi, 4(1), 12-19.

Ramandha, A., Kusmindari, D., \& Hardini, S. (2020, October). Pelaksanaan Total Productive Maintenance Terhadap Kinerja Bucket Wheel Excavator Melalui Cause Effect Diagram (Studi Kasus pada PT Bukit Asam, Tbk). In Bina Darma Conference on Engineering Science (BDCES) (Vol. 2, No. 1, pp. 340-354).

Zakaria, Z. (2006). Daya Dukung Tanah Fondasi Dangkal. Bandung Laboratorium Geologi Teknik, Jurusan Geologi, FMIPA UNPAD.

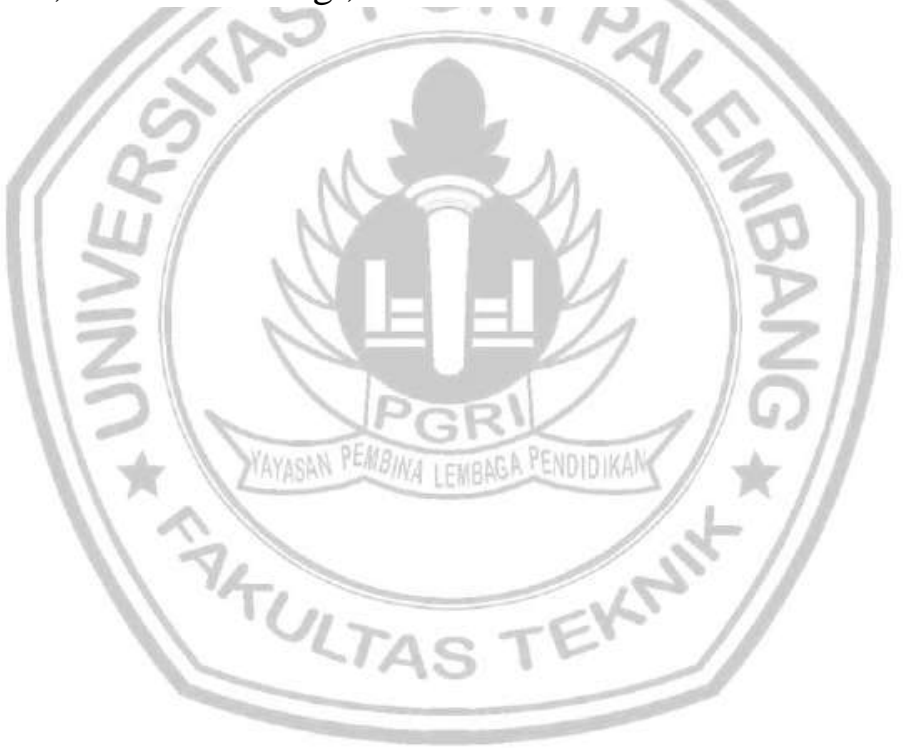

